\title{
Photothermal waterborne
}

\section{polydopamine/polyurethanes with light-to-heat conversion properties}

Cuneyt Erdinc Tas ${ }^{1,2}$, Ekin Berksun $^{1}$, Deniz Koken ${ }^{1}$, Serkan Unal ${ }^{1,3}$ and Hayriye Unal ${ }^{*}$

${ }^{1}$ Faculty of Engineering and Natural Sciences, Sabanci University, Istanbul, 34956, Turkey

${ }^{2}$ SUNUM Nanotechnology Research Center, Sabanci University, Istanbul, 34956 Turkey

${ }^{3}$ Integrated Manufacturing Technologies Research and Application Center, Sabanci University, Istanbul, 34956, Turkey

\section{Corresponding Author}

* Hayriye Unal, hunal@sabanciuniv.edu
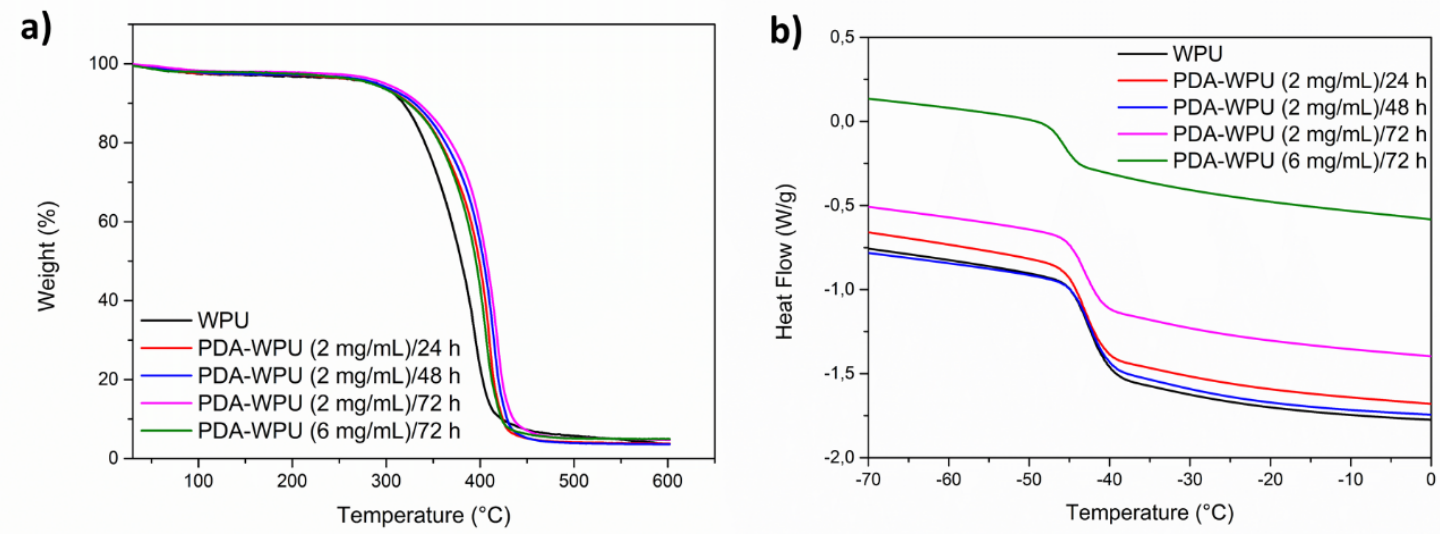

Figure S1. TGA (a) and DSC (b) curves of WPU and PDA-WPU films. 
a)

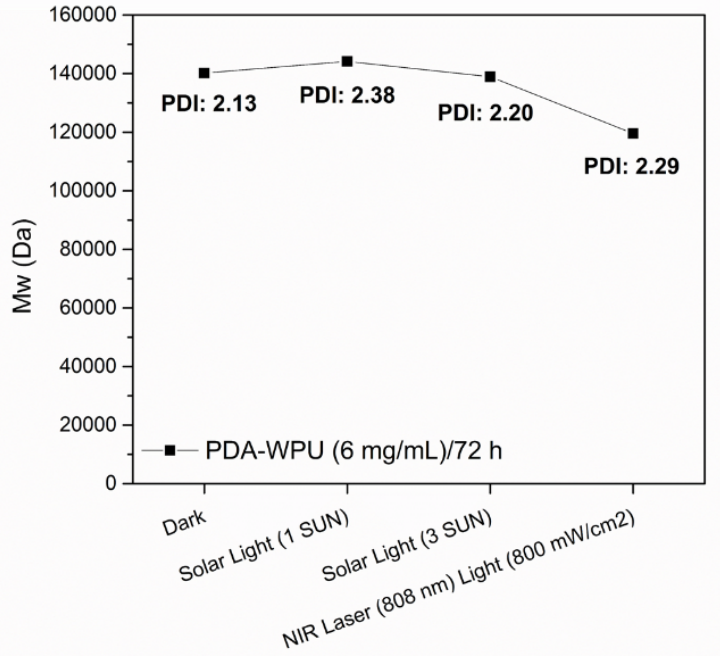

b)

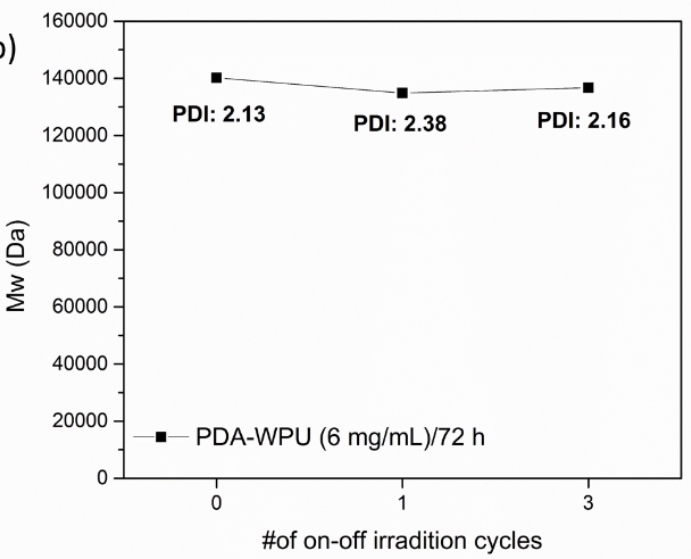

c)

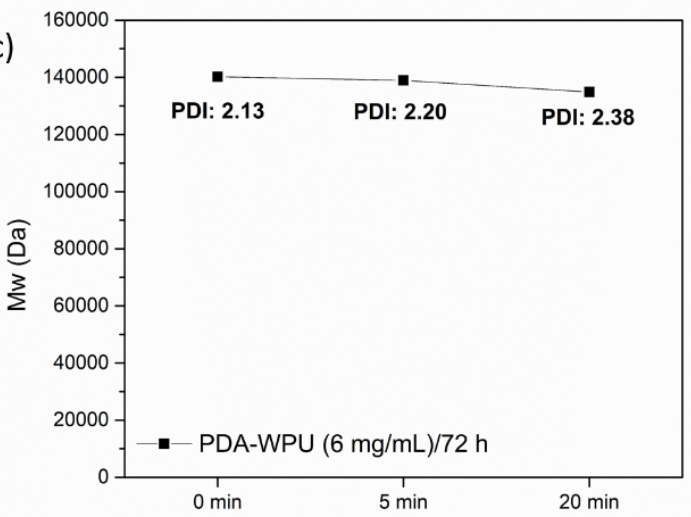

Figure S2. Weight average molecular weight (Mw) and polydispersity index (PDI) of PDAWPU (6 mg/mL)/72 h films irradiated with different light sources for $5 \mathrm{~min}$ (a), exposed to different number of on-off solar irradiation cycles at $3 \mathrm{SUN}$ for 20 min (b), irradiated with sunlight at 3 SUN for different durations (c). 


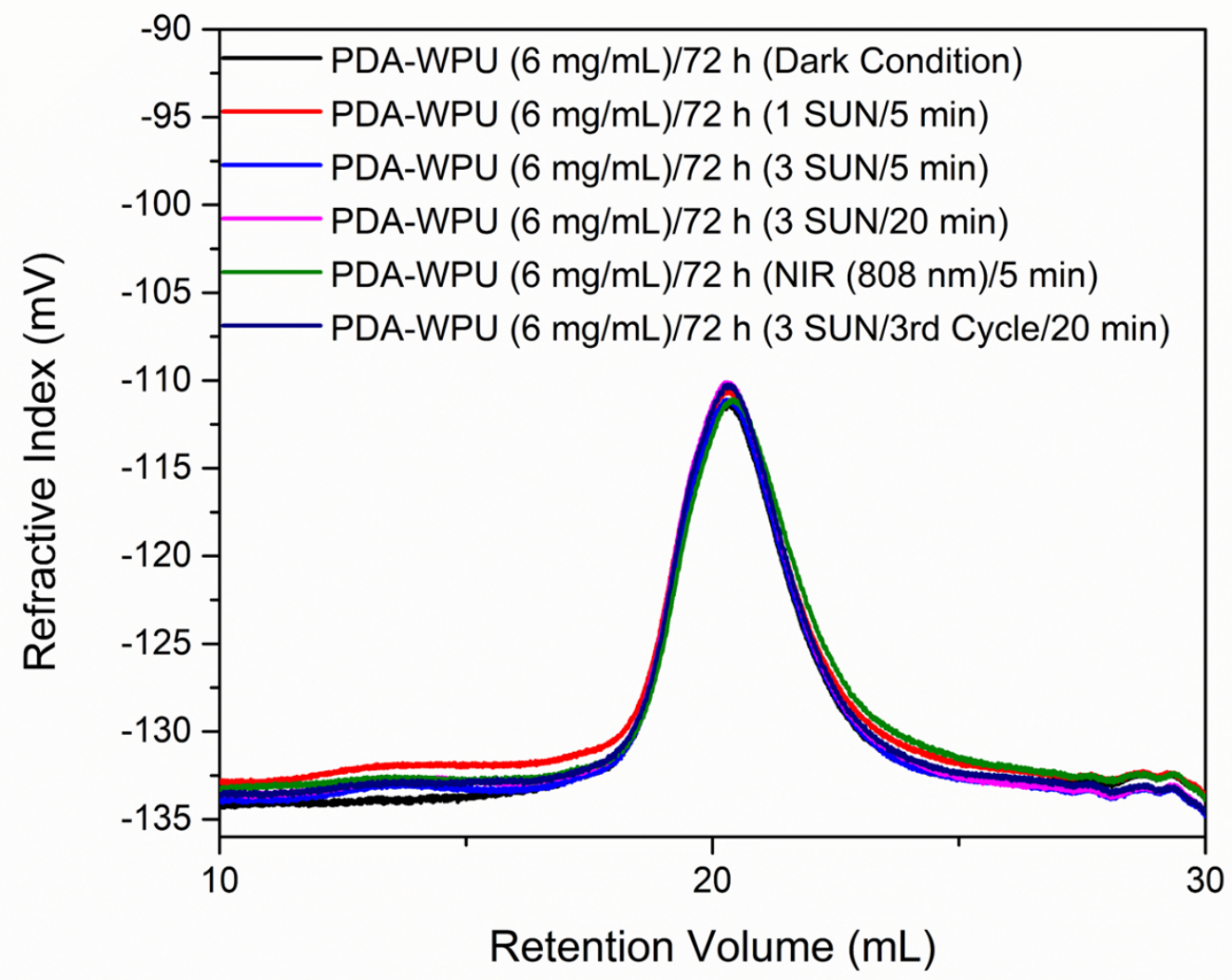

Figure S3. GPC curves of PDA-WPU $(6 \mathrm{mg} / \mathrm{mL}) / 72 \mathrm{~h}$ films irradiated with light under different conditions. 